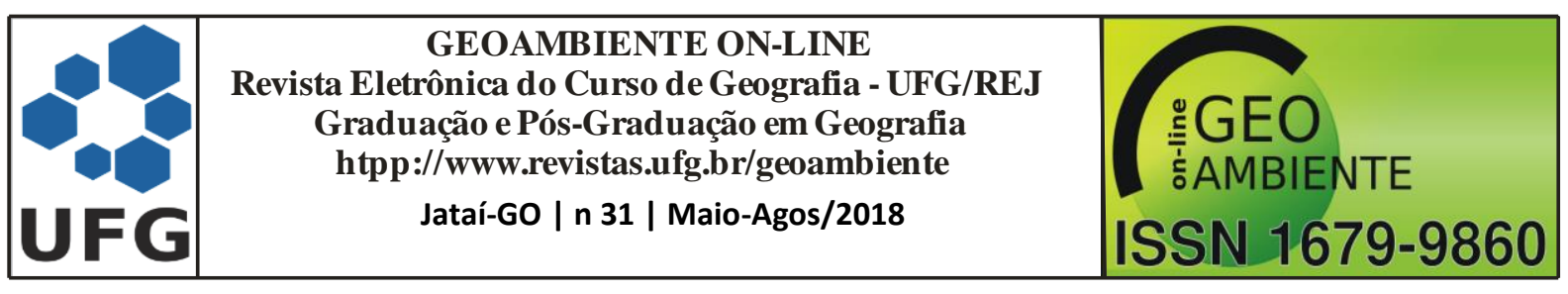

\title{
ANÁLISE DE CONFLITOS SÓCIOAMBIENTAIS NAS RESERVAS EXTRATIVISTAS DE SÃO JOÃO DA PONTA E CURUÇÁ- PA
}

Geise Corrêa Teles ${ }^{1}$ Márcia Aparecida da Silva Pimentel²

(1-Universidade Federal do Pará- UFPA, Mestra em Geografia, geise-corrêa@ hotmail.com; 2-Universidade Federal do Pará- UFPA, Professora Adjunta do Departamento de Geografia, mapimentel@ufpa.br)

Resumo: As Unidades de Conservação de uso sustentável tem por objetivo compatibilizar a conservação e utilização dos recursos naturais, contudo mesmo em áreas legalmente protegidas existem conflitos entre os moradores locais, a população que vive ao entorno, e até mesmo entre eles e as regras que regulamentam o uso desses recursos nas UCs. Nesse contexto o presente artigo buscou analisar os conflitos territoriais entre as Reservas Extrativistas de São João da Ponta e Curuçá-PA. Para elaboração da pesquisa foram desenvolvidos trabalhos de campo e entrevistas semiestruturadas. As informações coletadas subsidiam o debate para a ampliação da gestão participativa nas duas Unidades de Conservação.

Palavras-chave: Paisagem, Território e Gestão Participativa.

\section{ANALYSIS OF SOCIO-ENVIRONMENTAL CONFLICTS IN THE EXTRACTIVE RESERVES OF SÃO JOÃO DA PONTA AND CURUÇÁ-PA}

Abstract: Conservation Units for sustainable use aim to make the conservation and use of natural resources compatible, but even in legally protected areas there are conflicts between the local residents, the population living in the surroundings, and even between them and the rules that regulate the use of these resources in UCs. In this context the present article sought to analyze the territorial conflicts between the Extractive Reserves of São João da Ponta and Curuçá-PA. Fieldwork and semi-structured interviews were developed for the elaboration of the research. The information collected subsidizes the debate for the expansion of participatory management in the two Conservation Units.

\footnotetext{
Artigo recebido para publicação em 22 de Agosto de 2017
}

Artigo aprovado para publicação em 22 de Agosto de 2018 


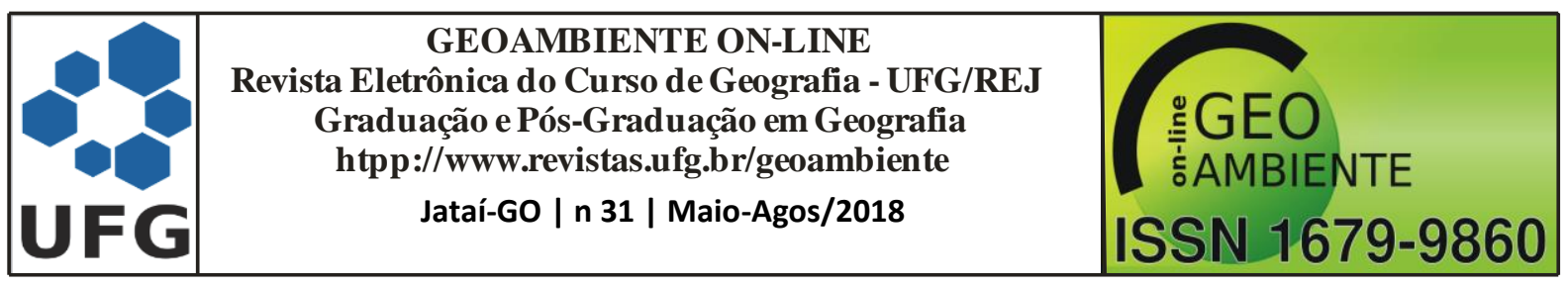

Keywords: Landscape, Territory and Participative Management.

\section{ANÁLISIS DE CONFLICTOS SOCIOAMBIENTALES EN LAS RESERVAS EXTRATIVISTAS DE SÃO JOÃO DA PONTA Y CURUÇÁ-PA}

Resumen: Las Unidades de Conservación de uso sustentable tienen por objetivo compatibilizar la conservación y utilización de los recursos naturales, sin embargo incluso en áreas legalmente protegidas existen conflictos entre los habitantes locales, la población que vive al entorno, e incluso entre ellos y las reglas que regulan el " el uso de estos recursos en las UC. En ese contexto el presente artículo buscó analizar los conflictos territoriales entre las Reservas Extractivas de São João da Ponta y Curuçá-PA. Para la elaboración de la investigación se desarrollaron trabajos de campo y entrevistas semiestructuradas. Las informaciones recolectadas subsidian el debate para la ampliación de la gestión participativa en las dos Unidades de Conservación.

Palabras-clave: Paisaje, Territorio y Gestión Participativa.

\section{Introdução}

Entre o município de São João da Ponta e Curuçá destaca-se o rio Mocajuba, que serve de limite entre as duas localidades, seu curso corre na direção Sudeste-Noroeste formando meandros, para depois tomar a direção Norte, até desembocar no Oceano Atlântico. A extensa cobertura de manguezais que acompanha o rio até onde ele recebe influência de maré, é protegida legalmente pela implantação das Reservas Extrativistas (RESEXs), criadas nesses dois municípios. Neste rio se desenvolvem duas das três principais atividades econômicas locais: a pesca e a coleta de caranguejo, além da reduzida extração de ostras, e ao entorno se desenvolvem atividades agrícolas.

A concentração de moradores ao entorno do rio Mocajuba com interesses nos recursos naturais comuns, gera espontaneamente conflitos entre eles. Observa-se também que além desses conflitos existem outros de ordem institucional, uma vez que envolve áreas de preservação ambiental e a influência do poder público municipal, assim também como há um choque entre a população local e a atuação dos agentes que configuram o uso dos recursos naturais nesses espaços, a exemplo das Unidades de Conservação (UCs). 


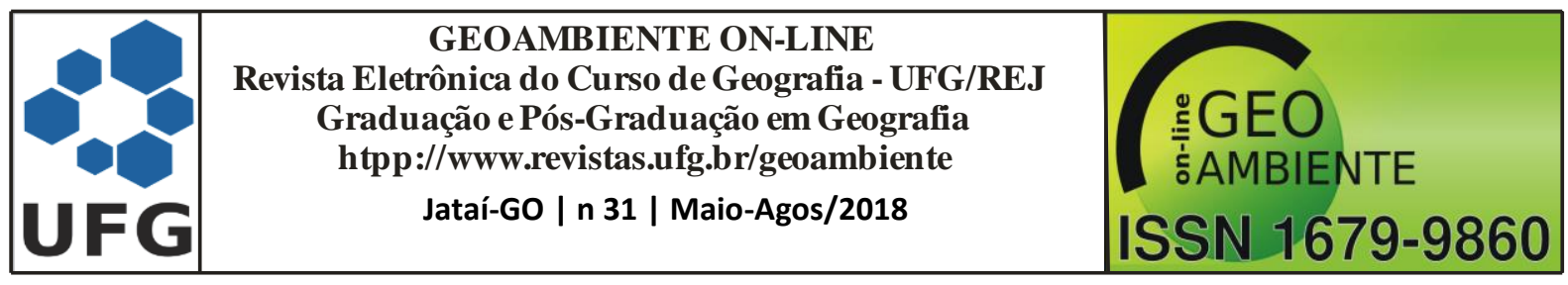

Os distintos interesses na forma de apropriação dos recursos naturais, e o controle sobre a forma de utilização desses recursos por mecanismos legais, como as normas que regulamentam a criação das Unidades de Conservação, mediante a atuação do poder público local, como as prefeituras, ou ainda os limites estabelecidos pelos próprios usuários dos recursos, uns em relação aos outros, como acontece nos territórios de pesca e criação de bancos de ostras. São na concepção dos moradores locais, os responsáveis pelos principais conflitos identificados no rio Mocajuba.

\section{Procedimentos Metodológicos}

Durante a pesquisa, que ocorreu entre março de 2015 e dezembro de 2016, foram realizados 10 trabalhos de campo, que incluíram atividades de observação, coleta de dados nas Reservas Extrativistas e articulação com a comunidade local. Os três últimos trabalhos de campo foram destinados a entrevistas semidirigidas.

Entre as 26 comunidades usuárias dos recursos do rio Mocajuba, foram selecionadas oito comunidades. Essas localidades foram escolhidas em função da influência que exercem sobre as comunidades ao entorno, a exemplo da Sede do município de São João da Ponta, e por demandas em relação à infraestrutura e articulação com as Unidades de Conservação locais. A viabilidade de acesso, e informações sobre áreas consideradas de maior conflito também foram fatores importantes na escolha dessas comunidades.

Das oito comunidades selecionadas, quatro estão localizadas a margem direita do rio Mocajuba, pertencentes a Reserva Extrativista de Curuçá, correspondem às comunidades: Beira Mar, Lauro Sodré, Candeua e Murajá. E quatro estão localizadas a margem esquerda deste mesmo rio, pertencentes à RESEX de São João da Ponta. Correspondem as comunidades: Deolândia, Sede, Coqueiro e Açu.

Segundo Passos (2013) as entrevistas semidirigidas funcionam como uma orientação do que deve ser perguntado aos entrevistados para obter informações importantes sobre a sua percepção em relação ao ambiente em que vivem. Esse tipo de entrevista possibilita uma abertura significativa às respostas dadas.

Foram entrevistadas duas pessoas de cada comunidade selecionada, uma com vínculo legal na RESEX, e outra sem vínculo com a Unidade de Conservação. Essa seleção foi feita, tendo em vista analisar a influência que as UCs têm na vida dos entrevistados, tanto no uso e 


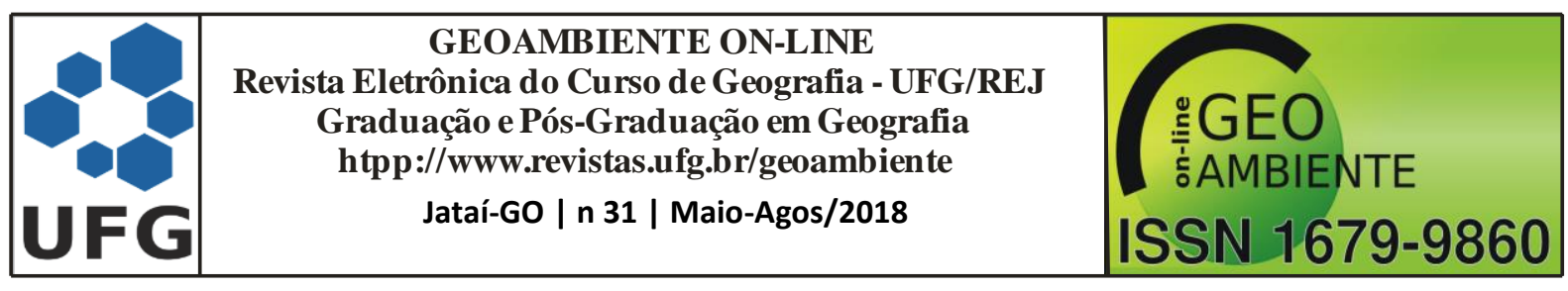

manejo dos recursos naturais, quanto na percepção desses indivíduos em relação ao seu ambiente de vivência. Ao todo foram entrevistados dezesseis moradores, oito na área territorial de São João da Ponta e oito na área territorial de Curuçá;

\section{Localização da Área de Estudo}

No mapa abaixo podemos observar a localização da área estudada, que corresponde à bacia hidrográfica do rio Mocajuba, uma área de uso comum entre as Reservas Extrativistas de São João da Ponta e Curuçá, ambas pertencentes aos municípios homônimos.

Figura 1- Mapa de localização das comunidades onde foram realizados os trabalhos de campo.

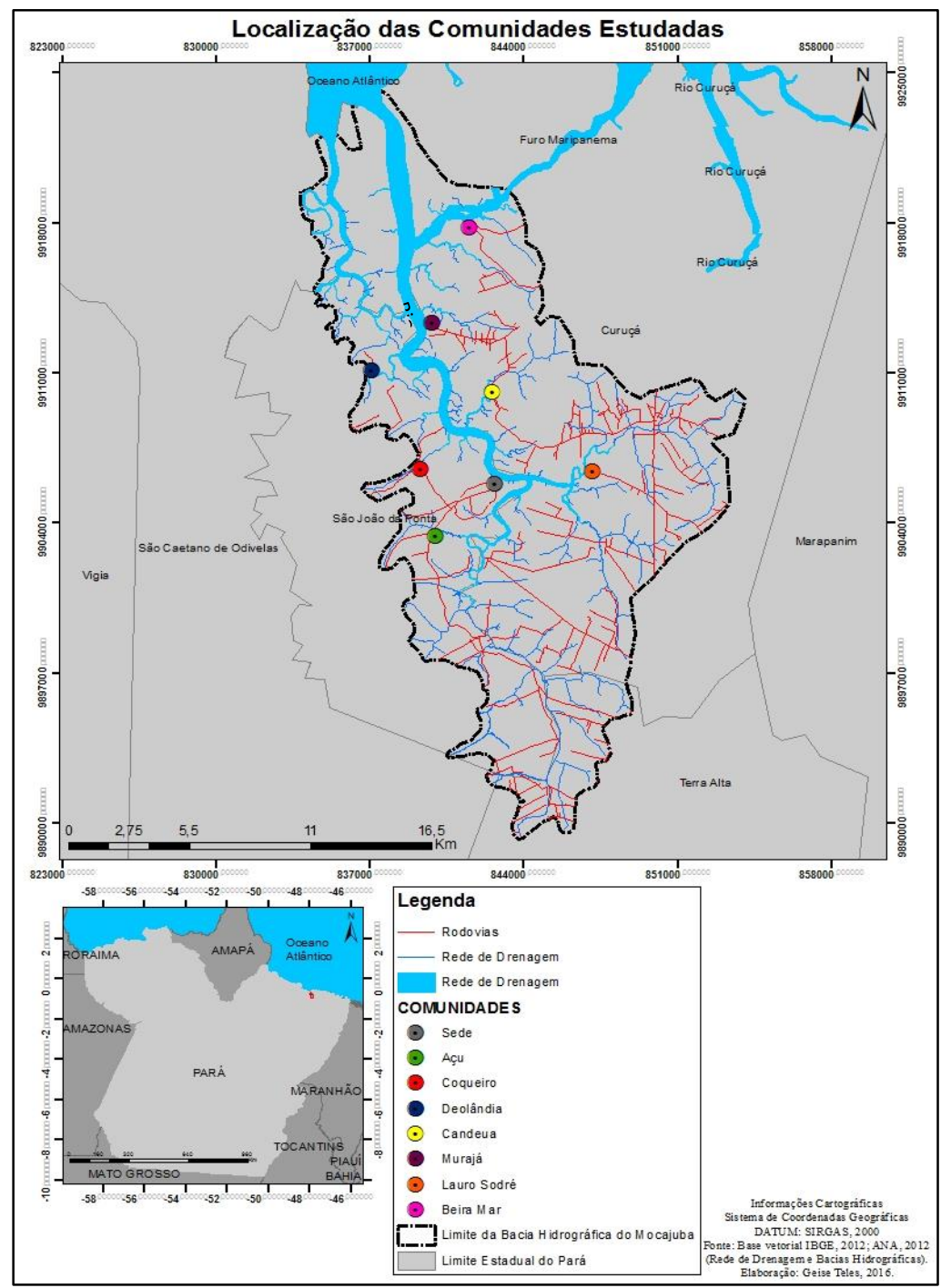

Fonte: Elaborado por Geise Teles, 2016. 


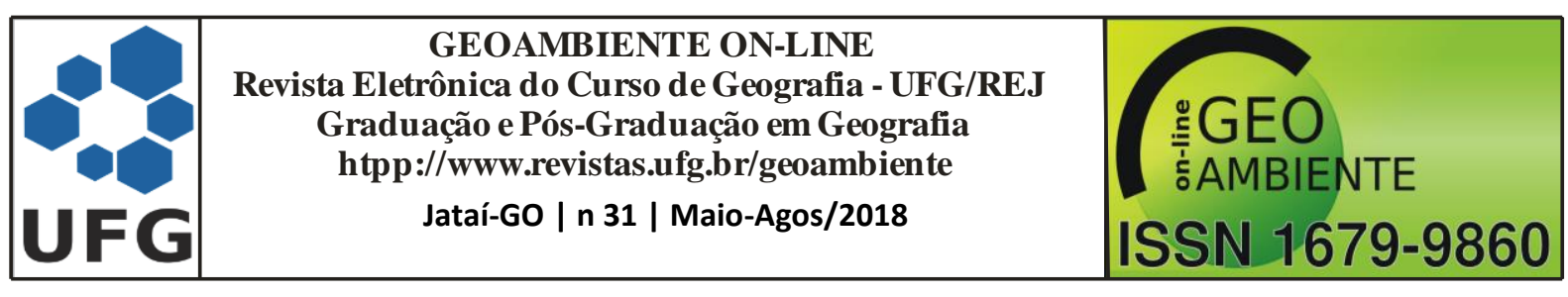

\section{As Diferentes Territorialidades e os Conflitos Sócioambientais}

A ampliação no horizonte de interpretação dos territórios, fez com que diversos conceitos fossem atribuídos ao mesmo. Destaca-se entre esses conceitos o proposto por Saquet (2009), que afirma que o "território é produzido espaço-temporalmente pelas relações de poder engendradas por um determinado grupo social". (SAQUET, 2009 p.223).

Esse conceito possibilita entender que o território resulta de relações de poder exercidas por grupos sociais, em um determinado período de tempo que lhes permitiu apropriar-se de uma área, lhe conferindo uma estrutura e funcionamento específicos, no âmbito econômico, político, cultural, simbólico ou de outra ordem.

As relações de poder representam o domínio que determinados grupos possuem sobre o território, esses domínios podem ser exercidos em múltiplas escalas, como na dimensão política de um município, por exemplo, mas também podem ser exercidos em territórios menores como territórios de pesca, no qual um grupo de pescadores pode exercer controle por um tempo.

Para Bertrand e Bertrand "territorializar o meio ambiente significa ao mesmo tempo, enraíza-los na natureza e na sociedade, fornecendo os meios conceituais e metodológicos de fazer avançar o conhecimento ambiental”. (BERTRAND e BERTRAND, 2009 p. 203). E um dos pontos fundamentais desse processo, seria observar os conflitos de ocupação desse ambiente.

O território seria para esses autores, um mecanismo de interpretação da realidade que permite analisar por meio das relações de poder, a apropriação do meio natural, o meio ambiente em construção.

Analisar as transformações no ambiente, como propõem os autores acima, significa analisar as mudanças estabelecidas nas formas de apropriação dos recursos, assim como as mudanças nas relações de poder postas, que podem ou não terem sido mediadas por conflitos. As relações de poder e apropriação resultam por tanto na construção dos diferentes territórios, que deixam suas marcas impressas na paisagem.

Nesse contexto o processo de territorialização pode ser entendido como "o efeito da ação territorial, representado por três aspectos indissolúveis entre si: material, simbólico e imaterial”, que acontecem por meio da denominação, delimitação, transformação material, 


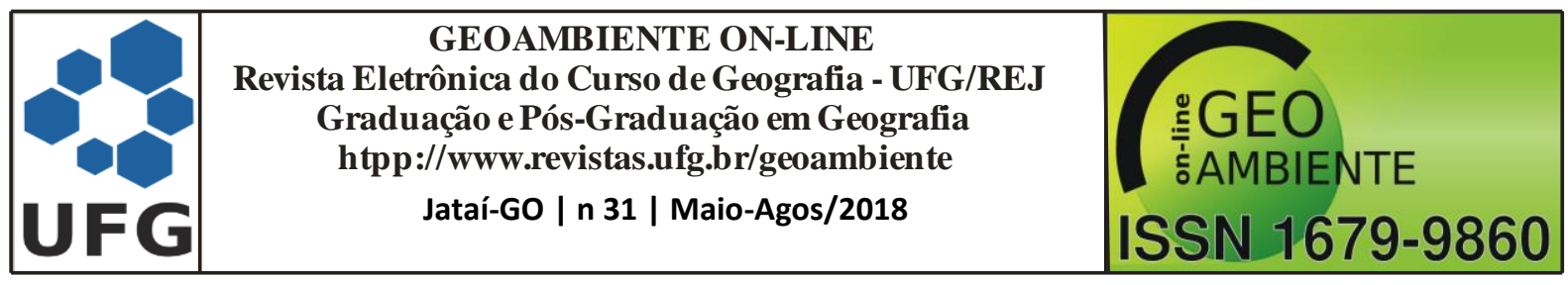

comunicação e estruturação específicas de um território (MACHADO e SAQUET, 2011 p. 130).

A experiência territorial dos indivíduos é distinta em um mesmo ambiente, por exemplo, tomamos como base as comunidades pertencentes ao município de São João da Ponta que vivem na margem esquerda do rio Mocajuba, dessas comunidades a Sede é a que mais possui serviços de infraestrutura urbana, as demais comunidades oferecem uma condição bem menor de infraestrutura, apresentam uma relação mais estreita com a natureza, suas formas de lazer e trabalho dependem em maior grau do meio natural, enquanto que na Sede, essa ligação é menos perceptível.

Isso quer dizer que a relação que o indivíduo estabelece com o seu espaço de vivência, maior ou menor contato com natureza, seja por meio do trabalho, lazer ou outra forma de apropriação do ambiente, revelam informações importantes de como ele percebe esse meio, pois sua percepção é projetada pelas experiências que emanam desses contatos.

O mesmo acontece com moradores mais antigos, e os recém-chegados, pessoas idosas e pessoas mais jovens. Pois o acúmulo de experiências, a vivência e afinidades com um lugar, introduzem na percepção desses indivíduos, uma relação de pertencimento e reconhecimento de distintas paisagens, que vão distinguir nas experiências dessas pessoas a relação com o ambiente em que vivem.

A territorialidade é, portanto, a materialização dos territórios, não apenas do ponto de vista estrutural, mas das relações estabelecidas nos espaços que são carregados de significados, experiências e vivências inerentes à forma como o individuo se introduz no ambiente. A territorialidade, nesse sentido não pode ser pensada fora da natureza e nem alheia à percepção dos indivíduos ou grupos organizados territorialmente.

Os diferentes usos e apropriações dos recursos naturais fazem do território uma ferramenta importante no entendimento das relações de poder que se instituem nas distintas paisagens, ou seja, dos conflitos ambientais que configuram a paisagem, como produto das territorialidades.

O papel social de cada indivíduo, pescador, coletor de caranguejo, agricultor ou comerciante, o cotidiano, a relação com natureza, à relação com o mercado, a relação com as Unidades de Conservação, o tempo de vivência na comunidade, para além de criar sua territorialidade, revelam as diferentes paisagens presentes no imaginário de cada um, 


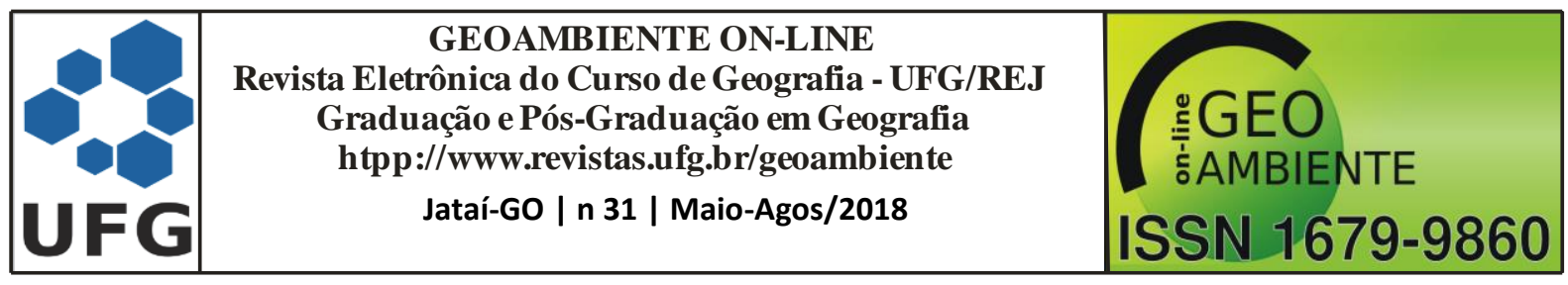

paisagens que são carregadas de significados construídos e atribuídos cotidianamente por relações sociais, econômicas e culturais, que resultam da vivência individual e coletiva desses indivíduos, num tempo e espaço social determinado.

\section{Resultados e Discussão}

A territorialidade é marcada, pelo movimento de apropriação e reprodução das relações sociais, no tempo e no espaço, material e imaterial da vida cotidiana, é uma interação relacional-processual, passível de mudanças, encontros e desencontros, conflitos, desigualdades e diferenças (SAQUET, 2013). A territorialidade é um campo de forças, que emerge na apropriação e utilização dos recursos naturais e os torna pertencente a um determinado grupo, que por apropriação e dominação exerce poder naquele lugar, esse poder constrói os diferentes territórios e territorialidades.

Um conflito ocorre quando grupos sociais distintos disputam a utilização e apropriação de um determinado recurso, que pode ser natural, econômico ou social. Quando a natureza se torna recurso, ela envolve inerentemente questões sociais e econômicas, e muitas vezes políticas, dependendo da dimensão e magnitude do conflito, por essas razões os conflitos por recursos naturais, são enquadrados como sendo de ordem ambiental. (LEFF (2003); LASCHEFSKI e ZHOURI, (2010)).

\section{Gestão da Unidade de Conservação X Prefeitura Local}

A cobertura de manguezais do Salgado Paraense é legalmente protegida por Unidades de Conservação, á área de proteção é marcada por uma linha de trinta metros em relação ao ecossistema manguezal, fora desse limite o ambiente é de propriedade do poder público local. Ações predatórias como, queimadas, acúmulo de resíduos sólidos e retirada da cobertura vegetal são muito recorrentes ao entorno das Reservas Extrativistas, como foi observado na área estudada. Contudo não existe um plano de ações ambientais, do ponto de vista legal, para regular essas ações predatórias, que por incidência direta ou indireta podem ser extremamente prejudiciais aos manguezais.

Os planos de ações das RESEXs, aprovados em assembleias e chamadas públicas que dão direito a voto aos principais representantes locais, são eles: um membro do poder público local, geralmente um vereador ou secretário, representantes das comunidades locais, e os 


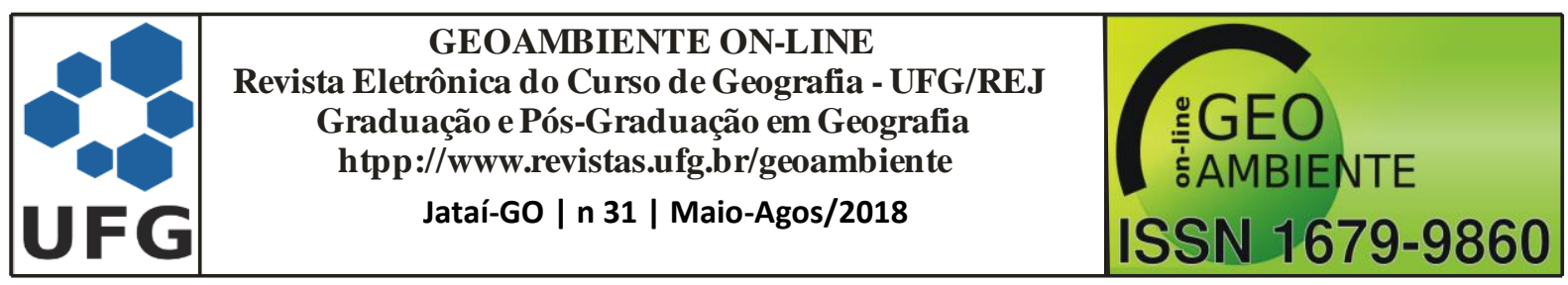

usuários cadastrados na Unidade de Conservação, não incluem ações para o entorno da UCs, pois essas ações demandam investimento financeiro, e uma articulação mais efetiva com o poder público local, o que não acontece devido aos interesses divergentes.

Os representantes da Reserva Extrativista Mãe Grande de Curuçá, que gerenciam os recursos da margem direita do rio Mocajuba, alegam ter boa relação com o poder público local, que segundo eles ajuda na manutenção da Unidade de Conservação enquanto fiscalizador de práticas predatórias nos limites da RESEX, contudo quando se questiona a respeito do plano de ações para o entorno da UC, coloca-se que o investimento político tem outras prioridades, além da questão ambiental municipal, por isso que qualquer ação de cunho ambiental, na visão dos moradores locais é pensada como de responsabilidade da RESEX.

No caso da Reserva Extrativista de São João da Ponta, que gerencia os recursos da margem esquerda do rio Mocajuba, os interesses políticos distintos dificultam a criação de um plano de ações para o entorno da Reserva. Pois tal como acontece em Curuçá, a questão ambiental não é uma prioridade do poder público local.

Uma questão interessante que envolve as Unidades de Conservação e a política municipal é a apropriação que se faz de discursos ambientalistas principalmente em épocas de campanha eleitoral. Nesse período geralmente os candidatos buscam articulação com as Reservas Extrativistas, pois elas possuem vínculo direto com a população local.

O problema é que essas 'articulações' que em grande parte são sustentadas por laços pouco consistentes, feitos em épocas de campanha, e desfeitos depois das eleições, trazem consequências, mais do que para os políticos, que possuem um histórico de descrédito, para as próprias Unidades de Conservação, que passam a ser vistas pelas populações locais, como representantes da estrutura política vigente, quando na verdade buscavam soluções, é claro que isso também não as isenta de defender determinados interesses políticos.

O descrédito político a qual as UCs ficaram associadas dificultam suas ações junto às comunidades locais, principalmente aquelas em que os resultados são pensados em longo prazo, tal como as ações de sensibilização ambiental. Na busca de aliados para atender seus interesses as RESEXs acabaram criando uma visão negativa sobre suas atuações para muitos moradores locais, e nesse jogo constante de proteção do seu território, busca apropriar-se novamente dessa confiança. 


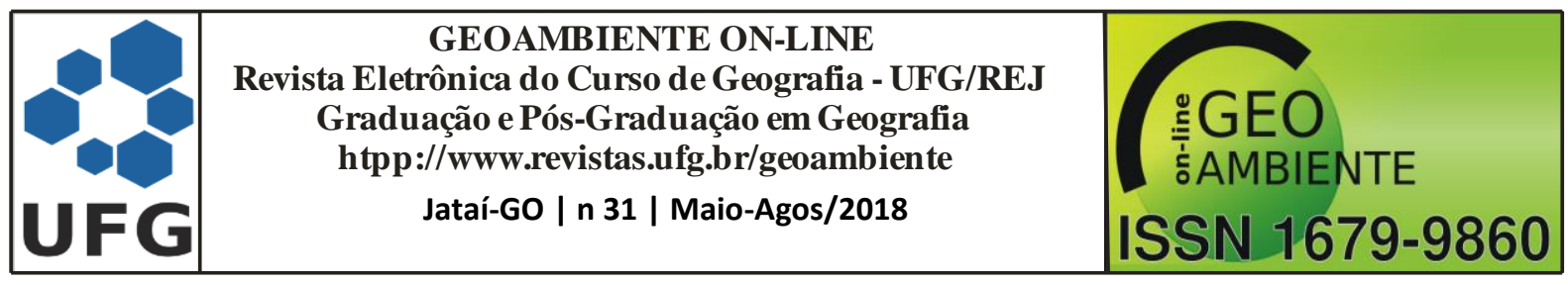

Um dos caminhos para resgatar essa confiança é o atendimento das demandas levantadas pelas comunidades. A melhoria na saúde, educação e transporte, que são as maiores carências desses lugares, mas que só poderão ser efetivadas na articulação com a prefeitura local, com vistas na melhoria da questão ambiental. É esse canal de articulação entre a comunidade, a gestão do poder público local e a gestão da RESEX que precisa ser fortalecido. Diante da descrença de algumas comunidades, somente ações concretas podem despertar novamente esperança em fazer parte de uma gestão participativa.

\section{Conflitos em Áreas de Pesca no Rio Mocajuba}

Os territórios da pesca são reconhecidos pela população local, pela existência de linhas demarcatórias que foram construídas simbolicamente durante a implantação das comunidades locais e que vão se redesenhando com o passar dos anos. No rio Mocajuba e seus afluentes, cerca de mil pescadores, de São João da Ponta e Curuçá exercem domínios sobre os seus recursos pesqueiros. Alguns pescadores de São Caetano de Odivelas, localizado a oeste do rio Mocajuba, e do município de Terra Alta, localizado a montante deste mesmo rio, também pescam esporadicamente nessa área.

Os territórios de pesca são reconhecidos e aceitos pelas comunidades usuárias do rio Mocajuba, obedecendo aos limites municipais. Os pescadores da margem direita do rio Mocajuba, pertencentes ao município de Curuçá, reconhecem os territórios dos pescadores da margem esquerda do rio Mocajuba, pertencentes ao município de São João da Ponta, e também são reconhecidos por esses. Os conflitos ocorrem em áreas comuns de pesca, que são as áreas do rio que não pertencem a nenhum município, mas que ao mesmo tempo pertencem a todos os usuários.

A lei que costuma vigorar nesses territórios comuns de pesca é de quem se apropria primeiro do recurso, e como existem alguns pontos estratégicos, que são observados como pontos de maior incidência do pescado, áreas mais próximas à desembocadura do rio, por exemplo, o conflito torna-se inevitável. Nesse contexto, os que possuem os melhores barcos e o maior número de pescadores trabalhando, costumam levar vantagem nas áreas comuns de pesca. A produção da pesca para o mercado, desenvolvida pelas comunidades da margem direita do rio Mocajuba, e o menor grau de produção do pescado nas comunidades da margem 


\begin{tabular}{|c|c|c|}
\hline & $\begin{array}{c}\text { GEOAMBIENTE ON-LINE } \\
\text { Revista Eletrônica do Curso de Geografia - UFG/REJ } \\
\text { Graduação e Pós-Graduação em Geografia } \\
\text { htpp://www.revistas.ufg.br/geoambiente } \\
\text { Jataí-Go | n } 31 \text { | Maio-Agos/2018 }\end{array}$ & $\begin{array}{c}\text { :GEO } \\
\text { JEAMBIENTE } \\
\text { G }\end{array}$ \\
\hline
\end{tabular}

esquerda desse rio, onde a pesca é mais voltada para a subsistência, revela que os pescadores de Curuçá dominam a maioria dessas áreas comuns de pesca.

Contudo considerar como único fator que as comunidades usuárias do rio Mocajuba, pertencentes ao município de São João da Ponta, não intensificam a produção pesqueira, devido unicamente a esses conflitos pode ser um grande equívoco, pois como foi visto existe um histórico de apropriação dos recursos naturais nessa área. A intensificação da produção em cada comunidade tem uma forte relação com a disponibilidade de recursos nela presentes, o que pode justificar de certa forma a intensa produção do caranguejo ao invés da pesca, nas comunidades pertencentes a São João da Ponta, que é mantida pela articulação com o mercado.

Outro conflito que ocorre nessas áreas comuns de pesca é a presença 'dos de fora', os 'de fora' são todos aqueles pescadores que não residem nas comunidades que margeiam o Mocajuba, sejam eles pertencentes a municípios vizinhos, como São Caetano de Odivelas, por exemplo, ou mesmo outras comunidades pertencentes a São João da Ponta e Curuçá. Esses pescadores não são muito bem-vindos, pois geralmente não obedecerem ao período do defeso, e utilizam apetrechos de pesca proibidos pelas Reservas Extrativistas. Os pescadores do rio Mocajuba sentem-se mais ameaçados por esses indivíduos 'de fora', do que por aqueles que eles já conhecem e disputam os recursos, pois eles sabem que as técnicas predatórias praticadas pelos 'de fora' são prejudiciais à captura futura do pescado, podendo levá-los a desaparecer.

Apesar das práticas predatórias apontadas ainda serem recorrentes, mostra-se interessante o discurso de muitos pescadores sobre a finitude dos recursos naturais, e sua necessidade de conservação para que as gerações futuras possam usufruí-los. Esse discurso vem daqueles que mantém contato com a RESEX, do qual sua comunidade faz parte, e são eles que afirmam que o manejo sustentável tem contribuído para o aumento da produção. Almejam pela maior fiscalização para eliminação de práticas predatórias não só na pesca, mas também na coleta de caranguejo e cultivo de ostras. A fiscalização é de suma importância, contudo observa-se que no caso dessas comunidades, ações de sensibilização ambiental são fundamentais, pois a partir dessa 'tomada de consciência', eles mesmos vão se tornando seus próprios fiscais, como já acontece em algumas comunidades, como a Sede do município de São João da Ponta. 


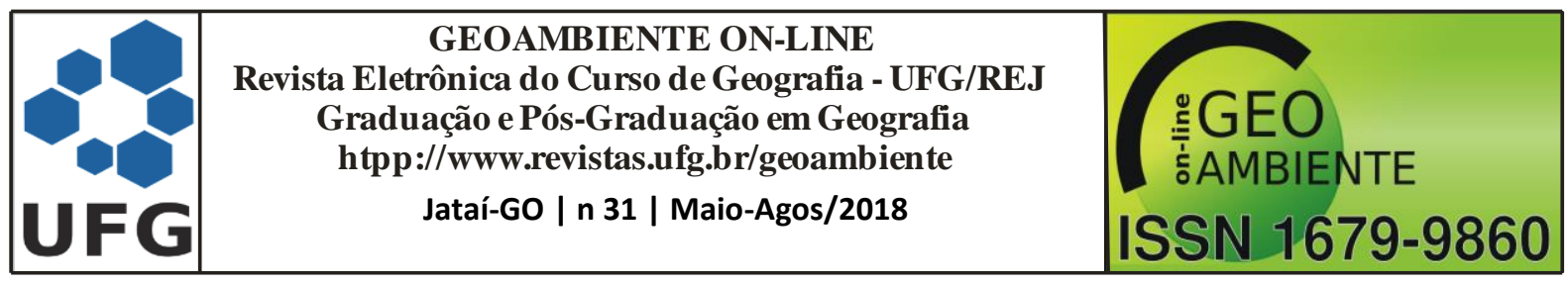

Está em processo de construção um plano de gestão compartilhada entre as RESEXs de São João da Ponta e Curuçá, que visa gerir os recursos naturais do rio Mocajuba, esse plano de gestão surgiu de uma demanda para amenizar conflitos em áreas comuns do rio, e um desses conflitos é o que ocorre pela pesca. A regulamentação desse plano e a atuação direta de suas diretrizes podem ser uma saída para os conflitos de pesca no rio Mocajuba, e é uma alternativa de resgate para aqueles que estão desacreditados da atuação das UCs nessa área.

\section{Conflitos pela Captura de Ostras no Rio Mocajuba}

A maior incidência de conflitos pela captura de ostras no rio Mocajuba se dá nas comunidades Deolândia e Açu, margem esquerda do rio Mocajuba, e na comunidade Lauro Sodré, margem direita do mesmo rio. Os conflitos ocorrem quando os bancos de ostras, sejam naturais ou artificiais, são roubados. Em Deolândia e Açu, quase todos os bancos de ostras naturais foram destruídos devido à retirada incorreta do molusco, os poucos moradores que tentaram a produção artificial, foram vítimas de roubos e acabaram desistindo do cultivo, e os que ainda manipulam os bancos naturais, são vítimas constante de furtos. Segundo os moradores locais, os principais suspeitos de cometerem esses crimes são os usuários da margem direita do rio Mocajuba, os moradores da comunidade Lauro Sodré.

$\mathrm{Na}$ comunidade Lauro Sodré, como já foi mencionado, existe uma significativa produção de ostras. A maior parte da produção é artificial, produzida por meio de bancos naturais. Nessa comunidade vários moradores trabalham individualmente com a produção de ostras, assim como também em outras comunidades usuárias do rio Mocajuba, a maioria não participa de Associações, realiza o trabalho por conta própria, essa informalidade no processo produtivo, gera desconfiança da origem da produção vendida, que é reforçada pela fragilidade da fiscalização local.

O viés lucrativo que a Associação dos Aquicultores da Vila de Lauro SodréAQUAVILA, localizada na comunidade Lauro Sodré, assumiu na concepção dos moradores locais, a torna rival de todos aqueles que produzem individualmente bancos de ostras, sejam naturais ou artificiais na comunidade. Esse conflito entre os produtores individuais de ostras da comunidade Lauro Sodré, e a Associação AQUAVILA, ocorre porque a maioria deles já 


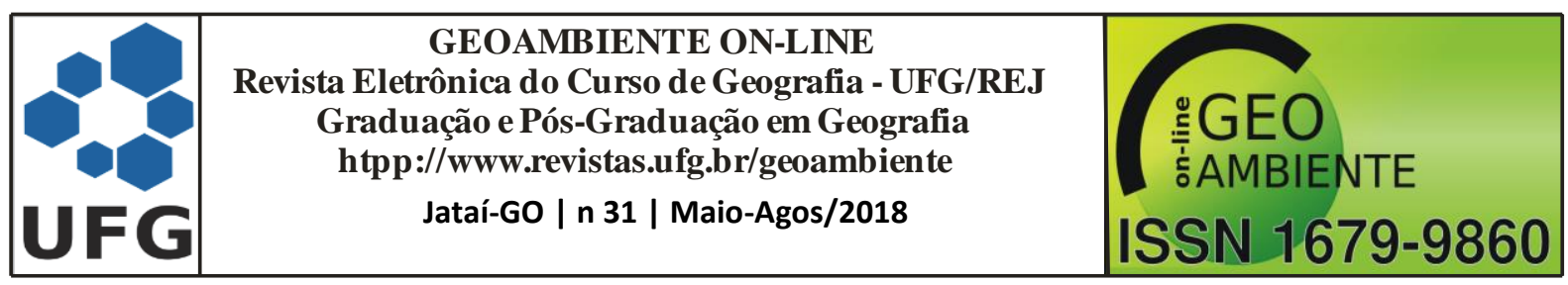

fez parte dessa Associação e se sentiu prejudicado devido à relação de parentesco nela presente e, sobretudo, pela imposição da lógica produtiva de mercado.

Um dos pontos observados que mais divergem entre esses dois grupos produtores de ostras é como aponta Reis (2005), a alteração na lógica da produção, anteriormente tradicional, pois o controle do tempo, do trabalho, da produção e da própria vida pessoal, exigido pelo caráter mercadológico da Associação AQUAVILA, diverge da pequena produção, da atividade que divide espaço com a pesca, e com a agricultura de subsistência. Em outras palavras, a implantação da lógica de produção imposta pela AQUAVILA estabelece uma dinâmica que fragiliza a manutenção das relações coletivas característica da produção tradicional extrativista, por isso eles entram em choque.

O acordo de gestão compartilhada dos recursos naturais do rio Mocajuba, também é uma ferramenta importante para a produção de ostras, pois pode trazer mais visibilidade para essa atividade, e regulamentar as produções individuais de cada comunidade, a fim de intensificar a fiscalização e melhorar a produção. É uma proposta que prioriza não somente o lucro, mas a regularização dessa atividade, e para que isso aconteça é necessário saber quem está produzindo, e quanto está produzindo, a fim de que a produção seja garantida, no ritmo e disposição do extrativista local.

Entre as alternativas de preservação dos recursos naturais na bacia hidrográfica do Mocajuba, o maior desafio tem sido de envolver a população nesse processo. A sensibilização ambiental não é uma tarefa fácil, mas é o mecanismo mais viável na articulação entre os agentes produtores do território, pois possibilita a abertura de ações que reconhecem as nuances desse território, com direcionamentos que vão além de propostas, mostrando os benefícios trazidos por esse trabalho. Esse é um caminho longo, que no caso da área estudada, ainda está começando, o primeiro passo já foi dado, reconhecendo que embora os atores sociais envolvidos possam ter interesses divergentes, necessitam preservar os recursos naturais existentes para o bem coletivo.

Mudança na Estrutura Produtiva: Práticas de Manejo Tradicionais X Lógica Produtiva de Mercado

Embora sejam historicamente desenvolvidas pela população local, as atividades de subsistência enfrentam a resistência das 'novas gerações' em reproduzir essas atividades. 'As 


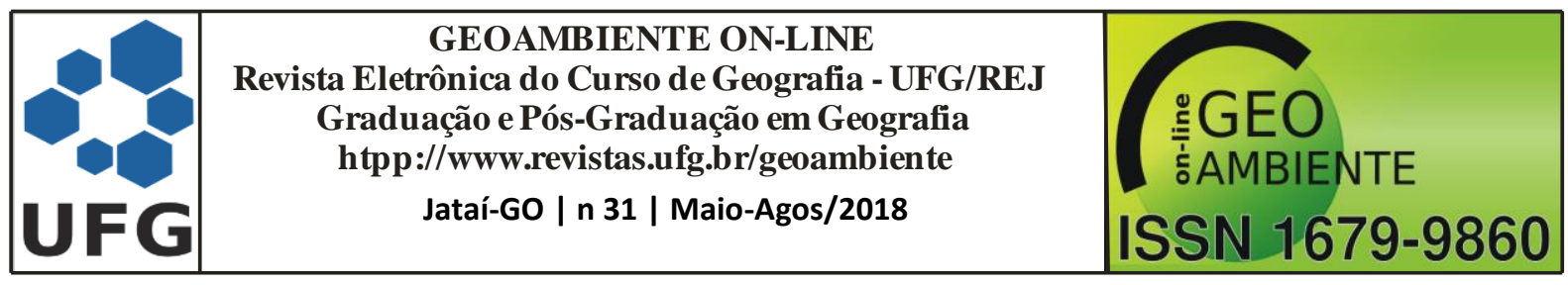

novas gerações', como apontam os relatos dos moradores locais, não se interessam em aprender os saberes tradicionais e as técnicas de manejo que as atividades exigem. A mentalidade dos jovens está associada à busca de empregos em outros ramos como o serviço público, e setores privados do município como lojas, mercados etc. A saída do município também é uma alternativa bastante considerada.

Mesmo vivendo em relativo isolamento físico, o contato com informações, sobre alternativas de vida distinta, desperta nos jovens o interesse em ter uma profissão diferente da dos pais e avós, pois muitos acreditam ou consideram pouco nobre o trabalho braçal nas lavouras e na pesca. A visão mercadológica da maioria dos jovens também contribui para a concepção de que as atividades de subsistência demandam muito trabalho e são pouco lucrativas. Por muito tempo essas atividades foram à única fonte de subsistência para a população local, mas a partir do momento que elas passaram a ser uma alternativa de vida e não a única alternativa despertam pouco interesse, sobretudo, num contexto da reprodução de uma visão mercadológica. É nesse contexto que os saberes tradicionais, se encontram ameaçados pela lógica de mercado.

Outra questão interessante observada no relato dos moradores locais é a presença cada vez mais numerosa de áreas desmatadas, nas proximidades do rio Mocajuba, essas áreas resultam de produções agrícolas abandonadas, pequenas áreas de pastagem e terrenos vendidos para moradores de outros municípios. Elas representam não só a presença 'dos de fora', que estão desenvolvendo cultivos mais intensivos, como também representam os espaços mais notáveis no desmatamento nas adjacências do rio Mocajuba. Os moradores das comunidades usuárias do rio Mocajuba, observam a presença 'dos de fora' como uma ameaça a produção local, uma ameaça que está sendo negligenciada por aqueles que vendem suas casas e terrenos, permitindo aos poucos a modificação de uma estrutura produtiva e social baseada em relações de compadrio e vizinhança.

A pressão mercadológica na região tem exigido mudanças no processo produtivo, que transformam a vida dos pequenos produtores, em 'profissionais' de uma única categoria de trabalho, que outrora se dividia em várias tarefas que lhe garantiam a subsistência e uma pequena renda no final do mês, mas agora eles são 'obrigados' a regular sua produção, seu trabalho, seu lazer, pois estão se inserindo numa nova lógica produtiva, como afirmam alguns estudiosos. (FURTADO, (1993); MANESCHY, (1993)). 


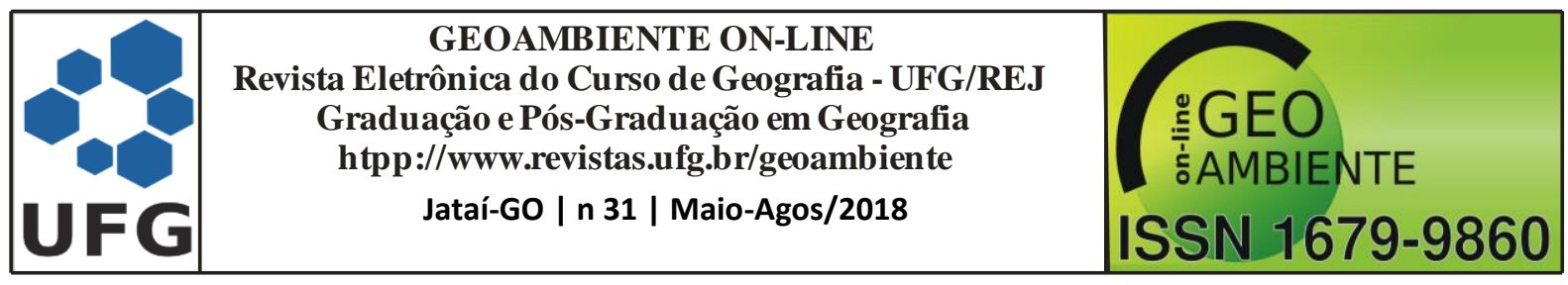

A inserção nessa nova lógica produtiva é mais visível nas comunidades da margem direita do rio Mocajuba, pertencentes ao município de Curuçá, onde o trabalho da pesca e da ostra obedece cada vez mais à lógica de mercado.

A coexistência dessas duas relações, uma imposta pelo mercado e a outra oriunda do manejo tradicional, revela duas territorialidades distintas. A territorialidade voltada para o mercado é acompanha de uma mentalidade que distancia cada vez mais os sujeitos do seu ambiente natural, à medida que as produções são terceirizadas, ou se especializam em uma única atividade. É uma mentalidade associada a 'melhoria de vida' baseada no consumo de bens materiais e ascensão econômica. O manejo tradicional não é contrário a essa mentalidade, mas se mantém baseado na pequena e diversificada produção, em que o tempo é controlado pelo trabalhador e não pelo cultivo, onde o controle da vida pessoal é mais importante que o consumo.

O aumento da produção é um incentivo aos extrativistas, pescadores e agricultores, assim como a busca por melhorias financeiras. Mas é necessário manter o suporte das pequenas atividades produtivas. Observa-se nessa conjuntura que as UCs atuam conciliando conservação e justiça social, a fim de que as práticas de manejo tradicionais não desapareçam, mas para que essas ações se concretizem é necessário que os diferentes interesses mostrados se direcionem para um único ponto o da conservação e manejo sustentável dos recursos naturais, que como foi visto, em função das distintas propensões não é uma tarefa fácil.

A tabela 1 mostra a síntese dos conflitos apresentados, tal como os sujeitos envolvidos nesses conflitos e soluções paliativas que devem ser urgentemente pensadas pelos gestores da área estudada.

\section{Contribuições para o Ordenamento Territorial: Gestão Participativa}

Nas situações analisadas, é possível observar a ausência da gestão participativa nas prefeituras locais, e em relação às Reservas Extrativistas o processo participativo ainda está incipiente, pois possui resistência de muitos moradores. $O$ investimento na gestão participativa pode ser a articulação que está faltando entre o poder púbico local, as Unidades de Conservação e a população, e mais do isso pode ser a chave na resolução dos problemas levantados, mas para que os interesses se tornem consensuais é preciso diálogo e que se trabalhe em favor da instância coletiva. 


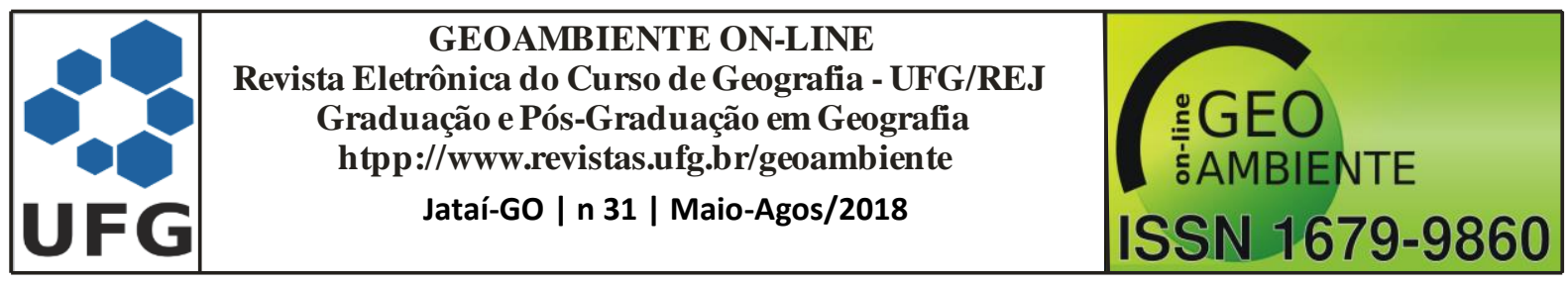

Tabela 1- Síntese dos Conflitos Identificados na Área Estudada, e proposta de Resolução desses conflitos.

\begin{tabular}{|c|c|c|}
\hline \multicolumn{3}{|c|}{ Conflitos Identificados na Gestão e Manejo dos Recursos Naturais } \\
\hline Tipos de Conflito & Sujeitos Envolvidos & Proposta de Resolução \\
\hline Gestão dos Recursos Naturais & $\begin{array}{c}\text { Unidade de Conservação X } \\
\text { Prefeitura Local }\end{array}$ & $\begin{array}{l}\text { Plano de Gestão entre as Prefeituras } \\
\text { e as Unidades de Conservação para } \\
\text { Áreas ao Entorno das RESEXs }\end{array}$ \\
\hline Áreas Comuns de Pesca & $\begin{array}{l}\text { Pescadores de São João da } \\
\text { Ponta X Pescadores de } \\
\text { Curuçá X “Os de Fora” }\end{array}$ & $\begin{array}{c}\text { Acordo de Gestão Compartilhada } \\
\text { entre as Unidades de Conservação, } \\
\text { e Práticas de Sensibilização } \\
\text { Ambiental }\end{array}$ \\
\hline Captura de Ostras & $\begin{array}{l}\text { Produtores Individuais de } \\
\text { Ostras X AQUAVILA }\end{array}$ & $\begin{array}{c}\text { Acordo de Gestão Compartilhada } \\
\text { entre as Unidades de Conservação, } \\
\text { e Práticas de Sensibilização } \\
\text { Ambiental }\end{array}$ \\
\hline $\begin{array}{l}\text { Mudança na Estrutura } \\
\text { Produtiva }\end{array}$ & $\begin{array}{c}\text { Práticas de Manejo } \\
\text { Tradicionais X Lógica } \\
\text { Produtiva de Mercado }\end{array}$ & $\begin{array}{l}\text { Fortalecimento das Ações das } \\
\text { Unidades de Conservação na } \\
\text { Manutenção das Pequenas } \\
\text { Atividades Produtivas Locais. }\end{array}$ \\
\hline
\end{tabular}

Fonte: Elaborado por Geise Teles, 2016.

Em função das demandas apresentadas pelos moradores, e da proximidade que as comunidades têm com os recursos naturais, a ampliação da gestão participativa permitirá aproximar os interesses dos moradores locais e órgãos gestores. Para que esse processo se desenvolva propõem-se quatro caminhos importantes e correlacionados:

Descentralização das decisões e autonomia das diversas instâncias criadas para o controle social e utilização dos recursos;

$>$ Qualificação de pessoas e grupos estratégicos com capacidade de intervir em processos que contribuam para a construção de uma sociedade mais democrática;

> Construção de projetos que trabalhem educação ambiental como instrumento para ampliar a capacidade de diálogo da população, no que diz respeito aos seus direitos e deveres sobre os recursos naturais;

$>$ É preciso criar uma articulação entre as instâncias maiores de poder.

O primeiro passo a ser trabalhado na ampliação da gestão participativa é a descentralização das decisões e controle sobre os recursos. Esse processo envolve um estudo sobre cada comunidade existente, suas demandas e perspectivas. Assim como dados 


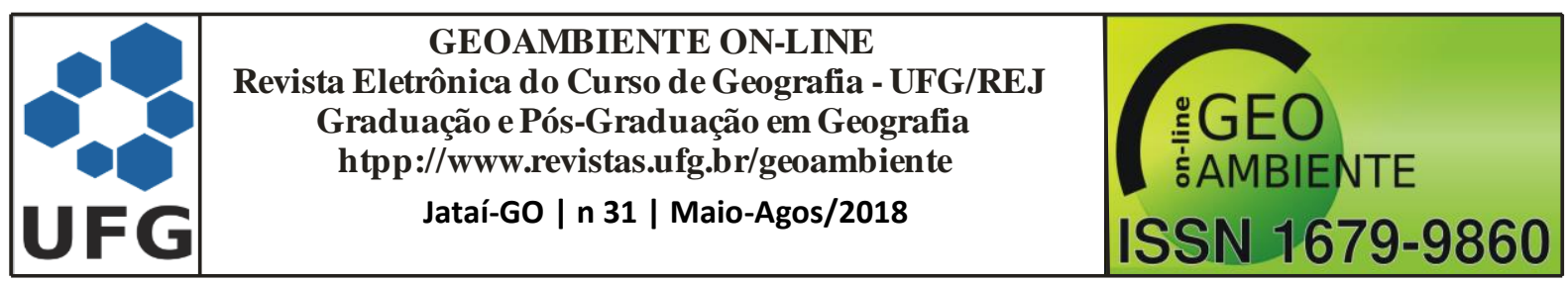

relacionados à própria população nela residente, após obter essas informações é necessário que se pense num sistema que envolva vários mecanismos de gestão sobre esses agentes.

As Unidades de Conservação que gerenciam os recursos do rio Mocajuba regularizam a gestão por meio de polos, que formam um conjunto de comunidades, que recebem influência de uma comunidade com o maior número de serviços, por isso diz-se que elas são polarizadas. Esse mecanismo de gestão é interessante porque ele ajuda no processo de descentralização do poder. Porém ele não garante que todas as comunidades estejam envolvidas no processo gestor.

A representação da população por comunidade é algo interessante para qualquer conselho gestor, contudo é mais difícil de ser executado, porque requer autonomia dessas localidades, e muitas se encontram enfraquecidas pelo próprio descaso político que julgam sofrer.

Uma das estratégias para cumprir tal missão é a qualificação de pessoas e grupos com capacidade de intervir em processos que contribuam para a construção de uma sociedade mais democrática. A qualificação de pessoas na macro e na micro escala envolve a participação em cursos de 'capacitação', e uma rede de articulação local que permita os indivíduos identificarem o seu papel no processo gestor e a importância que possuem como representantes das comunidades locais.

Em casos como o da área estudada, quanto mais estreito o vínculo com as comunidades locais, maior a possibilidade de ampliar e dar voz a essa população e, sobretudo, mostrar a heterogeneidade existente em ambientes que muitas vezes são tomados como homogêneos ou mesmo ignorados.

Acompanhando esse processo a educação ambiental deve ser utilizada como um instrumento que contribuí para disponibilizar informações qualificadas e atualizadas, compartilhar percepções e compreensões e ampliar a capacidade de diálogo e de atuação conjunta. Tendo em vista a leitura crítica da realidade buscando a produção coletiva do conhecimento na gestão participativa.

O investimento na educação ambiental é uma das ferramentas mais importantes no processo de gestão participativa, pois estimulará a consciência crítica, e possibilitará a população entender a realidade onde vive, considerando a importância que os elementos naturais possuem para a sobrevivência das comunidades locais. $\mathrm{O}$ entendimento da realidade 


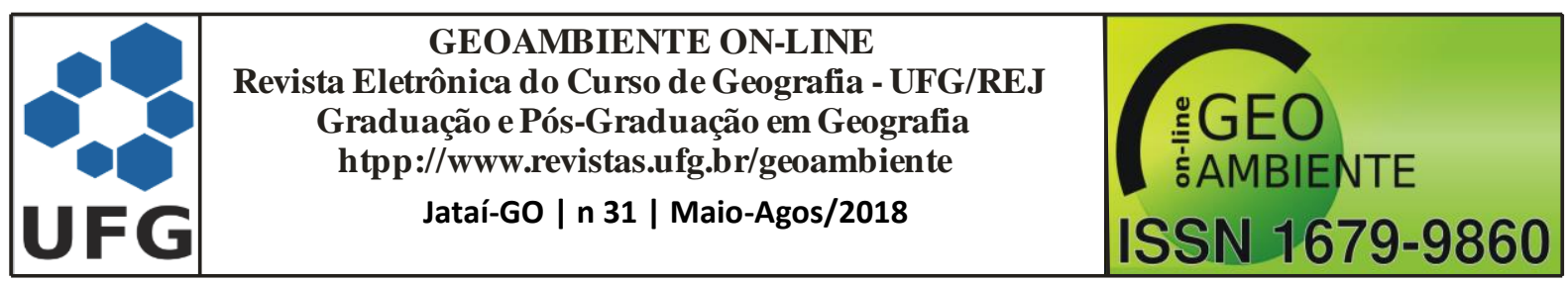

decorre de um processo de apropriação histórica sobre o ambiente onde vivem, esse processo envolve um mecanismo que busca trazer aos indivíduos a responsabilidade de suas ações.

A educação ambiental em conjunto com a percepção ambiental poderá criar as possibilidades de repensar o local, proporcionando aos indivíduos analisar a forma como vivem, suas fontes de satisfações e insatisfações. Isto contribuirá de forma bastante positiva ao estímulo da participação. A sociedade perceberá que o seu envolvimento nas discussões relacionadas à melhoria da qualidade ambiental, é que tornará possível a criação de instrumentos de gestão participativa e não mais soluções prontas para definir os procedimentos para o desenvolvimento sustentável.

Portanto o fortalecimento da gestão participativa depende da organização, e articulação entre as diversas instâncias de poder que regem o ambiente em questão. O desafio das UCs têm sido o de estreitar a relação entre os interesses da esfera federal, estadual e municipal, até o âmbito da população local. Observa-se na área estudada que existe um envolvimento da população na gestão da RESEXs locais, que se limita pelo desconhecimento de uma parcela considerável da população em relação à problemática ambiental. O contato com os indivíduos que apresentam uma visão esclarecida sobre o ambiente mostra que, ao serem envolvidos pelo processo de sensibilização ambiental eles encontram espaço na luta por um meio ambiente melhor, considerando o sentido mais amplo da palavra.

\section{Considerações Finais}

A utilização dos recursos naturais do rio Mocajuba é marcada por uma ocupação e apropriação conflitante, evidenciada por diferentes territorialidades, que se circunscrevem nas paisagens locais, e dão a elas aspectos representativos dos atores sociais que dela fazem parte. As diferentes territorialidades evidenciam, portanto, as transformações e feições atuais das paisagens, que possibilitam analisá-las e modificá-las, objetivando a melhoria das populações locais.

Com vista ao que foi apresentado considera-se fundamental criar um plano de ação para as áreas ao entorno das Unidades de Conservação, onde as práticas de degradação ambiental são mais frequentes. Para isso é de essencial importância à parceria entre as UCs e as prefeituras locais, que devem inicialmente trabalhar para que essas demandas sejam atendidas. $\mathrm{O}$ poder público local dos dois municípios citados não tem priorizado o meio 


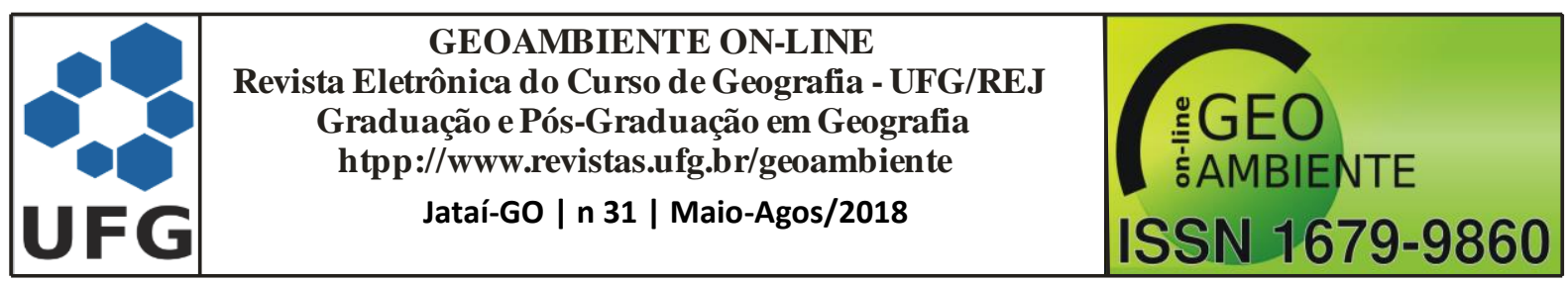

ambiente, fato que tem sobrecarregado as RESEXs, que enfrentam dificuldades de interação com a população devido à precariedade dos serviços públicos. Dessa forma, as políticas locais para essa área, devem estar objetivadas tanto na escolarização como no crescimento da renda da população e fundamentadas nas particularidades e nas dinâmicas da mesma, valorizando as riquezas culturais, o conhecimento tradicional, de maneira a contribuir para a fixação das pessoas em seu local de origem.

Diante do exposto coloca-se a afirmativa que a gestão participativa está no centro da resolução dos problemas apresentados, mas cabe ressaltar que o envolvimento no processo decisório deve ir além da simples comunicação, deve envolver essa população, o que significa consultar as pessoas, individualmente ou em grupo, sobre a solução de problemas por elas levantados como propõe o estudo aqui apresentado.

A visão distinta dos entrevistados que fazem parte das UCs e daqueles que não possuem ligação com elas, evidencia que as ações das RESEXs têm tido um efeito positivo em relação à preservação do meio ambiente e das práticas de manejo tradicionais. O que significa dizer que quanto mais a população estiver envolvida no processo gestor, mais ela terá esclarecimento sobre a necessidade de proteção do meio natural.

Em relação à área estuda, de todas as propostas apresentadas, considera-se que a educação ambiental seja o mecanismo mais importante de ampliação da gestão participativa, pois ela desperta nos indivíduos a "consciência" de fazer parte do processo de preservação ambiental, e abre os olhos para a necessidade de articular-se para gerir de forma adequada os recursos de uso comum. É um caminho logo, difícil, mas que tem dado bons frutos, que podem ser catalisados pelo desenvolvimento das propostas apresentadas.

\section{Referências}

BERTRAND, G.; BERTRAND, C. Uma geografia transversal e de travessias: o meio ambiente através dos territórios e das temporalidades. 2ª Edição. Maringá: Massoni, 2009.

FURTADO, L.G. Pescadores do Rio Amazonas: Um Estudo Antropológico da Pesca Ribeirinha numa Área Amazônica. Belém: Museu Paraense Emílio Goeldi, 1993.

LASCHEFSKI, K ; ZHOURI, A. Conflitos Ambientais Norte-Sul: Agrocombustíveis para quem? In: Alfredo Wagner Berno de Almeida et al (org.). Capitalismo Globalizado e Recursos Territoriais. Rio de Janeiro: Lamparina, v. 1. 2010. p. 1-350. 


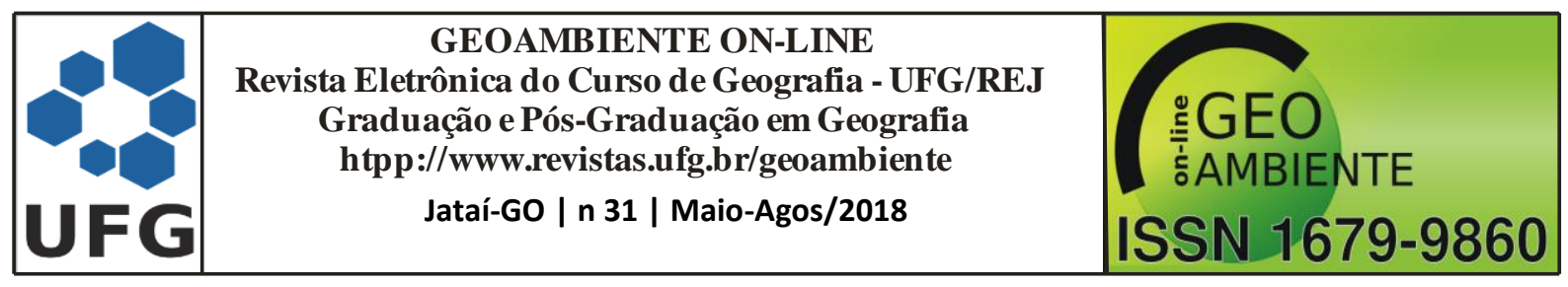

LEFF, E. Racionalidade Ambiental e do diálogo do conhecimento: Sentidos e caminhos de um futuro sustentável. In: FLORIANI, D;. Heemann, A. (orgs). Desenvolvimento e Meio Ambiente: $O$ diálogo de saberes e Percepção ambiental. Curitiba: Editora da UFPR, n.7. 2003. p.13-41.

MACHADO, G.; SAQUET. M. A. Espaço, Território, Paisagem: Em busca de uma ligação Conceitual. Revista Varia Scientia, Paraná. v.10, n.17. 2011. p. 119-135.

MANESCHY, M. C. Pescadores nos Manguezais: Estratégias Técnicas e Relações Sociais de Produção na Captura de Caranguejo. In: Povos das Águas: Realidade e Perspectivas na Amazônia. Org.: Lourdes G. Furtado, Wilma Leitão e Alex Fiúza, MPEG, Belém-Pará, 1993. PASSOS, M.M. Paisagem e meio ambiente (Noroeste do Paraná). $1^{\mathrm{a}}$ Edição. Maringá: Eduem, 2013.

REIS, M. R. Travesseiros, Redes e Conchas: Produção e Comércio de Ostras em áreas de RESEX. Anais do III Encontro Nacional da ANPPAS - (UNB) Brasília-Distrito Federal. 2005. p. 1-15.

SAQUET, M. A. Abordagens e concepções de território. $3^{\mathrm{a} e d}$. São Paulo: Expressão Popular, 2013.

SAQUET, Marcos A. Por Uma Abordagem Território. In: SAQUET, Marcos A.; SPÓSITO, Elizeu. S. Territórios e Territorialidades: Teorias, Processos e Conflitos. São Paulo: Expressão Popular, 2009. p. 73-93. 